ISSN: 2455-104X

Impact Factor: 4.950

Volume 4,Issue 1 (Jan-June) 2018, 52-59

Received: 15 June. 2018 ; Accepted: 28 June. 2018 ; Published: 06 July. 2018 ; Paper ID: IJRLS-1281

\title{
Bibliometric Analysis of the International Journal of Web Information Systems
}

\section{for the Year 2005-2015}

\author{
V.Santhanakrishnan ${ }^{1}$; P. Gomathi ${ }^{2}$ \\ Doctoral Research Scholar, Department of Library \& Information Science, \\ Periyar University, Salem-636011 ${ }^{1}$; \\ Assistant Professor, Department of Library \& Information Science \\ Periyar University, Salem-636011 2
}

vsanthanakrishnanacl@gmail.com ${ }^{1}$; gomathi148@periyaruniversity.ac.in ${ }^{2}$

\begin{abstract}
This paper deals with the analysis of the 212 original Contributions of the journal entitled "International Journal of Web Information Systems" published at the time of 2005-2015. The paper covers the bibliometric analyses of year-wise distribution of articles, category-wise classification of papers, geographical distributions and authorship patterns of the International Journal of Web Information Systems brought out during 2005-2015. The study finds that topmost number of citations was more than three authored (31.60 \%), and Category-wise classification of papers $84.90 \%$ citations were from Research Paper and come after by only $10.38 \%$ citations were from Technical Paper. The country-wise scattering of citations reveals that $32(15.09 \%)$ citations were from Japan and it was followed by Austria and USA.
\end{abstract}

Keywords: Bibliometric Study, Citation counts, International Journal of Web Information Systems.

\section{INTRODUCTION}

Periodicals are the primary source of information and an vital media for communication. They play a main role for communicating the latest research findings and publishing the articles containing the current development in any field of knowledge. Research is a prolonged process, aiming at discovering the truth and is a means for acquiring knowledge about any natural or human phenomena. Research in all fields is growing at a faster rate and particularly the field like Library and Information Science is advancing. This is due to the gradual change in the trends of research. In the process of identifying the research trends in a field, it is essential to analyse the various patterns that are evident in the literature in that field. Due to information explosion and multidisciplinary growth of subjects, it is very difficult to analyze the various patterns that are evident in the field. The bibliometric studies, which are mostly related to quantification of items and their pattern of distributions are useful in understanding some information phenomena and may help in planning many of the library activities. The first recorded study of Bibliometric topic was in 1971 by Coles and Eales with the 'Statistical analysis of literature on history of comparative anatomy; which served as a model for applying the counting technique in the evaluation 
of international activities (Cole and Eales,1971). Alan Pritchard first introduced the term Bibliometrices' in 1969 to mean 'the applications of mathematics and statistical methods to books and other media of communications (Pritchard,1969).

\section{International Journal of Web Information Systems:}

International Journal of Web Information Systems (ISSN: 1744-0084) is a well-known quarterly journal started publishing Online from 2005 published by Emerald Group Publishing, Ltd. The journal is intended for people interested in Web information systems and related areas at all levels. The primary audience of this journal includes academics, students, developers, engineers, innovators, research strategists and IT-managers who are looking visionary concepts and stimulating ideas in Web information systems at both the theory and application levels.

\section{Related Studies :}

Paramasivam and Venkatachalam review the journal titled "The Indian concrete" Journal from January 2012 to December 2012. The study revealed that utmost number of papers have been written by $23(39 \%)$ of two authors in the articles contribution, which shows collaborative research practice in The Indian Concrete Journal articles are especially cited from Journals, Books, Conferences, Proceedings and Technical Reports, ASTM standards.

Raina (1984) analysed citations of Annual Review of Biochemistry to check the stability of ranks of some significant journals of the subject.

Just Now surveyed on single journal bibliometric studies was conducted by Santhanakarthikeyan, Grace and Jeyshankar (2014) were studied the Indian journal of cancer and they were analysed 611 papers, $98.77 \%$ of the papers were multiauthored. Out of 22 countries contributed 244 research papers during the study period of the 244 articles, 168 (68.85 per cent) were published from India. In another study conducted by Gudodagi (2014) analysed highest number of research papers (14.27\%) was published in the year 2009. The study revealed collaborative research is high $(45.36 \%)$ most of the research papers give by Indians.

Shokeen and Kaushik (2004) studied the Indian Journal of Plant Physiology, volume 7. There are 61 articles with a total of 1,149 citations. Of the 61 articles, $19(31 \%)$ were contributed by three or more authors.

Sujatha and Padmini analyzed 3442 papers published in the journal IEEE Transactions on Antennas and Propagation during the period 2010-2014. They found that on an average 688 papers are published annually between the above said period. Number of publications in the journal from Indian authors was found to be very less as compared to European and Western countries.

\section{Objectives and methodology:}

$>$ To make an analysis of articles published in International Journal of Web Information Systems.

$>$ To ascertain the number of papers published in the International Journal of Web Information

Systems from 2005 to 2015

$>$ To investigate year-wise distribution of papers

$>$ To review the authorship pattern of papers

$>$ To examine geographical distribution of the articles state wise and country wise

\section{Scope :}

The present study analyses the contribution of Volume 1-11 (Year 2005-2015) of International Journal of Web Information Systems.

\section{Methodology:}

The methodology applicable in the current study is bibliometric scrutiny, which is used to analyses in detail the bibliographic attributes of the articles published in the International Journal of Web Information Systems from $2005-2015$. Eleven volumes (Vol. 01 to 11) containing 44 issues of the International Journal of Web Information Systems have been taken up for the study. The data for the study Scopus was used for collecting data and then used MS Excel to organize, tabulate and analyze the data for the study. 


\section{Data analysis and interpretation:}

The International Journal of Web Information Systems have extracted all the details such as author(s), year of publication, Geographical distribution, pagination etc of all articles published from 2005 to 2015 were recorded for the following analysis

During the period January 1, 2005 to December 31, 2015, 212 articles were published. Table 1 show that the numbers differs from year to year. Out of total 212 articles, the best numbers of articles are in the year 2015 contributing 24 articles, which are $11.32 \%$ to the total publications. The lowest numbers of articles are in the year 2010 with 16 articles, which are $7.55 \%$ to the total publications.

\begin{tabular}{|c|c|c|c|c|}
\hline Year & No. of Article & Percentage & Cumulative & Cumulative \% \\
\hline 2005 & 19 & 8.96 & 19 & 8.96 \\
\hline 2006 & 20 & 9.43 & 39 & 18.40 \\
\hline 2007 & 21 & 9.91 & 60 & 28.30 \\
\hline 2008 & 20 & 9.43 & 80 & 37.74 \\
\hline 2009 & 19 & 8.96 & 99 & 46.70 \\
\hline 2010 & 16 & 7.55 & 115 & 54.25 \\
\hline 2011 & 18 & 8.49 & 133 & 62.74 \\
\hline 2012 & 17 & 8.02 & 150 & 70.75 \\
\hline 2013 & 17 & 8.02 & 167 & 78.77 \\
\hline 2014 & 21 & 9.91 & 188 & 88.68 \\
\hline 2015 & 24 & 11.32 & 212 & 100.00 \\
\hline Total & 212 & 100 & & \\
\hline
\end{tabular}

Table 1. Year wise Distribution of Articles

Year wise Distribution

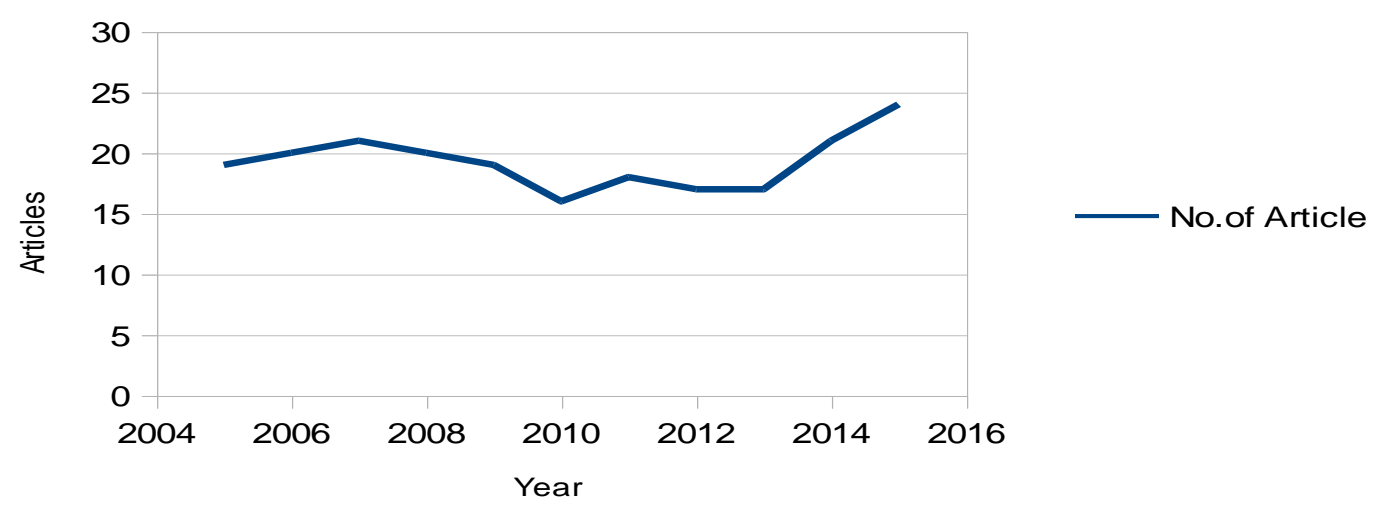




\section{Authorship patterns}

Table 2 reveals the authorship pattern of the articles published during the period of study. The huge number of articles had Three authors $67(31.60 \%)$. This is followed by more than three authors 60 (28.30\%), Two authors 58 (27.36\%) and single author with $27(12.74 \%)$ of the total articles.

Table 2. Authorship patterns

\begin{tabular}{|l|l|l|l|l|l|}
\hline Year/Author & Single & Two Author & Three Author & $\begin{array}{l}\text { More than Three } \\
\text { Author }\end{array}$ & Total \\
\hline 2005 & 1 & 4 & 8 & 5 & 18 \\
\hline 2006 & 2 & 3 & 3 & 2 & 10 \\
\hline 2007 & 4 & 8 & 10 & 8 & 30 \\
\hline 2008 & 5 & 5 & 6 & 5 & 21 \\
\hline 2009 & 2 & 7 & 6 & 6 & 21 \\
\hline 2010 & 0 & 3 & 7 & 5 & 15 \\
\hline 2011 & 3 & 4 & 7 & 3 & 17 \\
\hline 2012 & 2 & 6 & 6 & 3 & 17 \\
\hline 2013 & 4 & 4 & 5 & 5 & 17 \\
\hline 2014 & 4 & 8 & 3 & 5 & 22 \\
\hline 2015 & 0 & 6 & 67 & 60 & 212 \\
\hline Total & 27 & 58 & 31.60 & 28.30 & 100 \\
\hline Percentage & 12.74 & 27.36 & & 5 & 23 \\
\hline
\end{tabular}

\section{Type of Documents}

Table 3 indicates that the majority of the contributors preferred Research Paper as the source of information which occupied the top position with the greatest number of citations $180(84.90 \%)$ of the total 212 citations. The second highest position is occupied by online Technical paper with $22(10.38 \%)$ citations. It is followed by General Review with 4(1.89\%), Literature Review with 3(1.42\%), case study 2 ( $0.94 \%)$ and conceptual Paper 1(0.47\%). 
Table 3.Category-wise classification of papers

\begin{tabular}{|l|c|c|c|c|}
\hline Document Type & No. of Documents & Percentage & Cumulative & Cumulative \% \\
\hline Research Paper & 180 & 84.91 & 180 & 84.91 \\
\hline $\begin{array}{l}\text { Technical } \\
\text { Paper }\end{array}$ & 22 & 10.38 & 202 & 95.28 \\
\hline $\begin{array}{l}\text { Case } \\
\text { Study }\end{array}$ & 2 & 0.94 & 204 & 96.23 \\
\hline $\begin{array}{l}\text { Conceptual } \\
\text { Paper }\end{array}$ & 1 & 0.47 & 205 & 96.7 \\
\hline $\begin{array}{l}\text { General } \\
\text { Review }\end{array}$ & 4 & 1.89 & 209 & 98.58 \\
\hline $\begin{array}{l}\text { Literature } \\
\text { Review }\end{array}$ & 3 & 1.42 & 212 & 100 \\
\hline Total & 212 & 100 & & \\
\hline
\end{tabular}

\section{Geographical Distribution of Research:}

Table 4 gives that there are 212 publications during the study period. It has been identified that the greatest contributions is from Japan with $32(15.09 \%)$ publications, followed by Austria with 20 (9.43\%) contributions and occupies Second Position, USA contributed 16 (7.55\%) publications and occupied third position. Australia had 14 (6.6\%) publications and occupies fourth position and lowest number i.e., $1(0.47 \%)$ has been contributed from different Country i.e.,Algeria,Chile,Hong Kong,Iran,Ireland, Kuwait,Netherlands, Romania,Portugal ,India and Tunisia.

Table 4.Geographical Distribution

\begin{tabular}{|c|c|c|c|}
\hline S.No & Country / Countries & Articles & Percentage \\
\hline 1 & Japan & 32 & 15.09 \\
\hline 2 & Austria & 20 & 9.43 \\
\hline 3 & USA & 16 & 7.55 \\
\hline 4 & Australia & 14 & 6.6 \\
\hline 5 & Germany & 11 & 5.19 \\
\hline 6 & Canada & 9 & 4.25 \\
\hline 7 & Italy & 9 & 4.25 \\
\hline 8 & Saudi Arabia & 8 & 3.77 \\
\hline 9 & Brazil & 7 & 3.3 \\
\hline 10 & France & 6 & 2.83 \\
\hline 11 & Malaysia & 6 & 2.83 \\
\hline 12 & VietNam & 6 & 2.83 \\
\hline \multicolumn{4}{|c|}{ 2018, IJRLS All Rights Reserved } \\
\hline
\end{tabular}




\begin{tabular}{|c|c|c|c|}
\hline 13 & UK & 6 & 2.83 \\
\hline 14 & Taiwan & 5 & 2.36 \\
\hline 15 & Czech Republic & 4 & 1.87 \\
\hline 16 & Greece & 4 & 1.87 \\
\hline 17 & Spain & 4 & 1.87 \\
\hline 18 & China & 3 & 1.42 \\
\hline 19 & Colombia & 3 & 1.42 \\
\hline 20 & Finland & 3 & 1.42 \\
\hline 21 & New Zealand, & 3 & 1.42 \\
\hline 22 & Singapore & 3 & 1.42 \\
\hline 23 & Switzerland & 3 & 1.42 \\
\hline 24 & Argentina & 2 & 0.94 \\
\hline 25 & Egypt & 2 & 0.94 \\
\hline 26 & Norway & 2 & 0.94 \\
\hline 27 & Oman & 2 & 0.94 \\
\hline 28 & South Koria & 2 & 0.94 \\
\hline 29 & Sweedan & 2 & 0.94 \\
\hline 30 & Thailand & 2 & 0.94 \\
\hline 31 & UAE & 2 & 0.94 \\
\hline 32 & Algeria & 1 & 5.19 \\
\hline 33 & Chile & 1 & $0.47 \%$ \\
\hline 34 & Hong Kong & 1 & $0.47 \%$ \\
\hline 35 & Iran & 1 & $0.47 \%$ \\
\hline 36 & Ireland & 1 & $0.47 \%$ \\
\hline 37 & Kuwait, & 1 & $0.47 \%$ \\
\hline 38 & Netherlands & 1 & $0.47 \%$ \\
\hline 39 & Romania & 1 & $0.47 \%$ \\
\hline 40 & Portugal & 1 & $0.47 \%$ \\
\hline
\end{tabular}


Bibliometric Analysis of the International Journal of Web Information Systems for the Year 2005-2015

\begin{tabular}{|l|l|l|l|}
\hline 41 & India & 1 & $0.47 \%$ \\
\hline 42 & Tunisia & 1 & $0.47 \%$ \\
\hline & Total & 212 & 100 \\
\hline
\end{tabular}

Relative Growth Rate and Doubling Time

Table 5. RGR and DT

\begin{tabular}{|c|c|c|c|c|c|c|}
\hline Year & No. of Article & Cumulative & W1 & W2 & RGR & DT \\
\hline 2005 & 19 & 19 & & 2.94 & & \\
\hline 2006 & 20 & 39 & 2.94 & 3.66 & 0.72 & 0.96 \\
\hline 2007 & 21 & 60 & 3.66 & 4.09 & 0.43 & 1.61 \\
\hline 2008 & 20 & 80 & 4.09 & 4.38 & 0.29 & 2.41 \\
\hline 2009 & 19 & 99 & 4.38 & 4.6 & 0.21 & 3.25 \\
\hline 2010 & 16 & 115 & 4.6 & 4.74 & 0.15 & 4.63 \\
\hline 2011 & 18 & 133 & 4.74 & 4.89 & 0.15 & 4.77 \\
\hline 2012 & 17 & 150 & 4.89 & 5.01 & 0.12 & 5.76 \\
\hline 2013 & 17 & 167 & 5.01 & 5.12 & 0.11 & 6.46 \\
\hline 2014 & 21 & 188 & 5.12 & 5.24 & 0.12 & 5.85 \\
\hline 2015 & 24 & 212 & 5.24 & 5.36 & 0.12 & 5.77 \\
\hline Total & 212 & & & & & \\
\hline
\end{tabular}

Relative Growth Rate

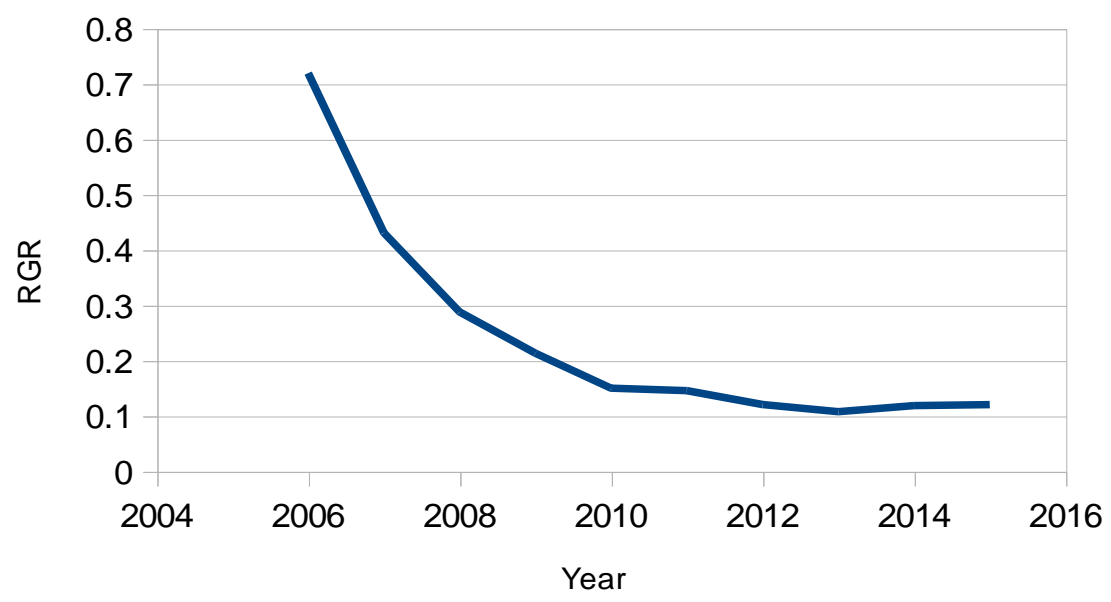

Fig1 


\section{Doubling Time}

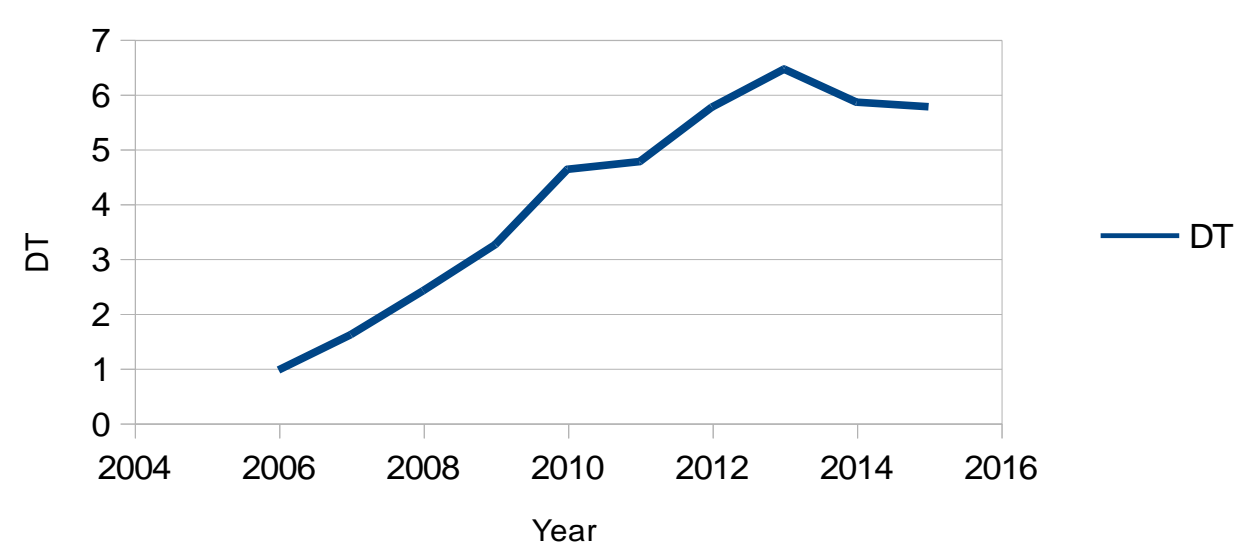

Fig2

\section{Relative growth rate(RGR)and Doubling time (Dt)}

It is seen from Table 4and Figure 1 that RGR has been decreasing from 2006 (0.72 to 2015(0.12).On the other hand, the Doubling Time (DT) has shown an increasing trend. The date in Table 5 reveals that Doubling time has increased from 0.96 in the year 2006 to 5.77 in the year 2015 (Figure 2)

\section{Findings and Conclusion}

There are total 212 publications published in International Journal of Web Information Systems in the year 2005 2015. The year 2015 has the topmost number of 24(12.04\%) publications, where as the year 2010 has lowest number of 16 (7.55\%) publications. It has been pinpont that the maximum contributions is from Japan with 32 (15.09\%) publications, come after by Austria with 20 (9.43\%) contributions and occupies second position, USA contributed 16 (7.55\%) publications and occupied third position. Australia had 14 (6.6\%) publications and occupies fourth position and lowest number i.e., 1 $(0.47 \%)$ has been contributed from several Country i.e.,Algeria,Chile,Hong Kong,Iran,Ireland, Kuwait,Netherlands,Romania,Portugal ,India and Tunisia.

On the other hand, journal refers to a record of events, experiences, thoughts, and observations kept on a regular basis by an individual for personal use. Writers often keep a regular journal to record ideas and material that may later be incorporated into their works.

\section{REFERENCES}

[1]. Borgman, C.L., and Furner, J, (2002), Scholarly communication and bibliometrics, Annual Review of Information Science and Technology, 36: 3-72.

[2]. Paramasivam. S. \& Venkatachalam, A, M.(2015). The Indian Concrete Journal- A Scientometric Study. Indian Journal of Science, 21(74), 571-579.

[3]. Raina, R. 1984. Study towards achieving stability in the ranks of some important journals in biochemistry. Annals of Library Science and Documentation, Vol.31, no.3-4: 162-7

[4]. Santhanakarthikeyan et al, (2014), Research publications to Indian Journal of Cancer: a scientometric analysis, Library Hi Tech News, 3, 21-25.

[5]. Shokeen, A.; \& Kaushik, S. K. (2004). 'Indian Journal of Plant Physiology': A citation analysis. Annals of Library and Information Studies, 51, 108-115.

[6]. Sujatha, D. \& Padmini, K. (2015). IEEE Transactions on Antennas and Propogation: A bibliometric study. DESIDOC Bulletin of Library \& Information Technology, 35(6), 443-449. 